\title{
El codesarrollo y las migraciones en la política española de cooperación internacional para el desarrollo
}

\author{
Alba Vallés Marugán \\ Universidad de Granada. Instituto de Migraciones \\ albavalles@ugr.es
}

Recepción: 10-07-2020

Aceptación: 25-03-2021

Publicación: 22-07-2021

\section{Resumen}

En el presente trabajo se abordan como objeto teórico de estudio los vínculos entre codesarrollo y migraciones en el contexto español. Para ello, se analiza la forma en que ambos fenómenos son plasmados en los principales documentos institucionales de la política española de cooperación internacional para el desarrollo. En primer lugar, veremos cómo se refleja el fenómeno migratorio y, en segundo lugar, abordaremos cómo se trata el concepto de codesarrollo. Concluiremos tratando de interpretar en qué medida estas políticas se ajustan a una triple concepción del codesarrollo: como herramienta de gestión migratoria, como herramienta de cooperación al desarrollo o como herramienta de integración. De esta manera, veremos cómo el abordaje de estos asuntos y la forma de concebir a las personas migrantes han ido evolucionando conforme a los cambios sociales y políticos vividos por el Estado español.

Palabras clave: codesarrollo; migraciones; cooperación al desarrollo; gestión migratoria; integración; análisis documental; políticas públicas

Abstract. Co-development and migration in the Spanish policy of International Development Aid

In this paper, we address the connections between co-development and migration in the Spanish context as a theoretical object of study. On this basis, we analyze the way in which both phenomena are reflected in the main institutional documents of the Spanish policy of International Development Cooperation. In the first place, we will see how the migration phenomenon is reflected and, secondly, we will address how the concept of co-development is treated. We will conclude by attempting to adjust these policies into a triple conception of co-development: as a migration management tool, a development cooperation tool or an integration tool. In this way we will see how the approach to these issues and the way of conceiving migrants have evolved according to the social and political changes experienced by the Spanish State.

Keywords: co-development; migration; development aid; migration management; integration; documentary analysis; public policy 


\section{Sumario}

\section{Introducción $\quad$ 5. A modo de conclusión}

2. ¿Qué entendemos por codesarrollo? Agradecimientos

3. Breve apunte metodológico Referencias bibliográficas

4. Codesarrollo y migraciones en la política española de Cooperación Internacional para el Desarrollo

Anexos

\section{Luchamos contra la pobreza y la desigualdad por justicia, no para} impedir que las personas migren.

J. M. Vera

\section{Introducción}

En el presente trabajo pretendemos llevar a cabo un primer acercamiento a la forma en que son plasmados el fenómeno migratorio y el codesarrollo en diferentes documentos de la política española de cooperación internacional para el desarrollo. En nuestra investigación buscamos conocer el fenómeno del codesarrollo, y para ello creemos esencial analizarlo desde el punto de vista institucional y centrarnos en el caso concreto de la cooperación, ya que entendemos que se trata de una de las políticas desde donde se plantean las acciones a llevar a cabo en este ámbito. En este sentido, desde la política migratoria europea ya se contempla el vínculo entre migraciones y desarrollo (Pinyol y Royo, 2010), y se menciona la colaboración (y cooperación) con terceros países, lo que ofrece un abanico más amplio de relaciones entre estados. Una vez contemos con el discurso institucional del codesarrollo, nos será posible acercarnos a las realidades prácticas emprendidas por diferentes actores, en que las personas migrantes ocupan un papel esencial.

En este sentido, el codesarrollo se ha erigido como un fenómeno relativamente reciente, si lo comparamos con los vínculos históricos establecidos entre cooperación y migraciones. Asimismo, la implicación de las personas migrantes en acciones de cooperación - $-\mathrm{o}$, simplemente, en acciones que las vinculen a sus lugares de origen y busquen, de algún modo, el desarrollo de sus comunidades - constituye un fenómeno que se ha venido dando desde siempre (Giménez et al., 2006; Aboussi, 2015) y que seguirá produciéndose, aunque no se acompañe de etiquetas específicas como de codesarrollo. Lo novedoso sería, así, emplear dicho término para referirse a ello (Giménez et al., 2006). Este concepto, pese a haber sido usado con anterioridad, fue popularizado a finales de los años noventa del pasado siglo por Sami Naïr, por aquel entonces secretario interministerial de Codesarrollo y Migraciones Internacionales del Gobierno francés. En su Informe de balance y orientación de la politica de codesarrollo en relación con los flujos migratorios (1997), Naïr lo concibió como una nueva forma de entender el vínculo entre migración y desarrollo y de poner en valor 
el papel de las personas migrantes en todos estos procesos de carácter transnacional (Garreta y Guillem, 2010). Desde ese momento, el codesarrollo ha ido evolucionando para adaptarse a los distintos tiempos y lugares, y ha variado de la mano de los diferentes actores, sus intereses y objetivos (Lacomba, 2010).

En el contexto español, el codesarrollo apareció estrechamente vinculado al planteamiento francés, así como a la política migratoria europea implementada desde el Consejo Europeo de Tampere (Cortés, 2004), donde, precisamente, se puso de relieve el binomio migraciones-desarrollo. Además, se plantea muy unido a la cooperación para el desarrollo (Giménez et al., 2006), ya que surge en un inicio en el contexto de la cooperación descentralizada (principalmente en la cooperación catalana), para luego ser institucionalizado en la política estatal de cooperación internacional para el desarrollo (Pinyol y Royo, 2010). Cabe destacar que, de algún modo, España constituye la frontera sur de Europa y, por lo tanto, tiene un rol esencial en la gestión de los flujos migratorios procedentes del Sur Global (básicamente, el continente africano). Para ello, pone en marcha una gran diversidad de herramientas que se supeditan a este objetivo, entre las que se incluye, precisamente, la cooperación al desarrollo.

El codesarrollo ha sido considerado por algunos autores como un fenómeno impreciso (Gómez y Unzueta, 2009), para el cual, ni siquiera durante el periodo en que este tuvo un mayor auge, no existió un consenso social y académico acerca de su validez y definición (Garreta y Guillem, 2010). Pero, pese a ello, en los más de veinte años transcurridos desde que Naïr pusiera sobre la mesa el codesarrollo, se han realizado múltiples investigaciones centradas en él, tanto dentro como fuera del contexto español. Estos trabajos han mostrado las diversas formas de concebirlo, así como las aportaciones que ha habido desde diferentes ámbitos. Sin embargo, a partir del año 2012 aproximadamente, el interés por el codesarrollo ha ido decayendo, tanto en el ámbito político como académico. Actualmente, se halla casi ausente en los documentos oficiales y cada vez menos presente en trabajos de investigación. Es más, la propuesta del codesarrollo parece haber tenido poca vida más allá de las políticas de cooperación al desarrollo francesas y españolas. En un trabajo muy reciente, Lacomba y Royo (2020) analizan algunas de las causas que han provocado esta desaparición del codesarrollo, y destacan cómo «la crisis económica que afectó a España a partir de finales de la primera década rebajó notablemente las expectativas en torno a su viabilidad, hasta el punto de que comenzó a hablarse del fin del codesarrollo" (p. 236). Por otra parte, abogan también por la posible relevancia de volver a incluir el discurso del codesarrollo vinculado a la Agenda 2030 y los Objetivos de Desarrollo Sostenible, lo que le podría situarlo de nuevo como objeto de interés de la esfera política en materia de cooperación.

En cuanto al fenómeno migratorio, este constituye un aspecto central en todo el mundo, con importantes implicaciones tanto políticas y económicas como socioculturales (Said, 1996). En nuestro contexto, a partir de los años ochenta, España se empezó a erigir como foco de inmigración (López-Sala, 2007; Gozálvez, 2012), de modo que se incorporó como tal en el sistema migratorio europeo (López-Sala, 2007). La inmigración laboral se sitúa como 
un fenómeno social y económico relevante, y la llegada de migrantes a España se ha caracterizado sobre todo por su diversidad, tanto por sus orígenes geográficos como por su distribución espacial en el Estado español (Gozálvez, 2012). Con este crecimiento de la migración, parecía «necesario e inevitable, en beneficio de todos los afectados por los flujos migratorios, potenciar acciones, políticas migratorias, y también estudios que conduzcan a buscar las mejores alternativas para aminorar progresivamente, mediante el desarrollo, los actuales flujos migratorios internacionales forzados» (Gozálvez, 2012: 170). En este sentido, en España no se desarrollaron mecanismos de regulación de la inmigración hasta los años ochenta, con la Ley Orgánica 7/1985, de 1 de julio, sobre Derechos y Libertades de los Extranjeros (López-Sala, 2007), conocida como ley de extranjería 1985, sometida a su primera reforma legislativa en el año 2000. A lo largo de los años noventa, se sigue avanzando en distintos acuerdos multilaterales, como es el caso del Acuerdo de Schengen (LópezSala, 2007). Por otra parte, como ya anunciábamos, en España se siguieron las pautas marcadas en el Consejo Europeo de Tampere, donde se establece la política de inmigración y asilo para la Unión Europea (Zapata-Barrero et al., 2008; Pinyol, 2019).

La inmigración fue ocupando un lugar muy relevante en el ámbito político (Zapata-Barrero et al., 2008), al abordar otras cuestiones vinculadas también a la integración de las personas migrantes y la colaboración con los estados emisores. Aquí, precisamente, ejercía un papel relevante la cooperación al desarrollo, pues, en este contexto, los países denominados en vías de desarrollo o del Sur Global se han convertido en polos emisores de migración, mientras que aquellos considerados desarrollados o del Norte Global se convertían en receptores de la misma. Así, el vínculo establecido entre migraciones y desarrollo pasa a ocupar un lugar esencial (Faist, 2010), pues estos estados constituyen a su vez, y respectivamente, los beneficiarios y donantes de la cooperación al desarrollo, canalizada bajo forma de ayuda oficial al desarrollo (en adelante, AOD).

Por ello, nos resulta interesante conocer la forma en que este fenómeno ha sido plasmado en el caso concreto de la política de cooperación del Estado español. En la actualidad, las políticas migratorias europeas se han tornado cada vez más hacia su vertiente securitaria, centradas en la lucha contra la inmigración irregular, lo que contradice los principios apuntados en Tampere y limita las opciones de los estados miembros (Pinyol, 2019), donde, como en España, se incorporan estos planteamientos en sus políticas de gestión migratoria, lo que afecta a su vez a las de cooperación internacional. Con todo esto, tras plantear una breve aproximación teórica al concepto de codesarrollo, en el presente trabajo se abordan como objeto teórico de estudio los vínculos entre codesarrollo y migraciones en el contexto español. Para ello, se analiza la forma en que ambos fenómenos son plasmados en los principales documentos institucionales de la política española de cooperación internacional para el desarrollo, a través de un análisis de los mismos basado en el marco de la antropología de las políticas públicas. En primer lugar, veremos cómo se refleja el fenómeno migratorio y, en segundo lugar, abordaremos cómo se trata el concepto de codesarrollo. 
Concluiremos tratando de interpretar en qué medida estas políticas se ajustan a una triple concepción del codesarrollo: como herramienta de gestión migratoria, como herramienta de cooperación o como herramienta de integración. A partir de este planteamiento, pretendemos dar respuesta a la pregunta que ha guiado el presente trabajo: ¿̇de qué forma aparecen contemplados el fenómeno migratorio y el codesarrollo, así como el vínculo entre ambos, en la política española de cooperación internacional para el desarrollo?

\section{2. ¿Qué entendemos por codesarrollo?}

Como ya hemos introducido, el codesarrollo constituye una forma de vincular positivamente el fenómeno migratorio y el desarrollo. Se promulga la cooperación entre países y la colaboración entre diferentes actores, de modo que todos ellos se ven beneficiados. Se insiste también en la implicación de las personas migrantes como agentes conscientes del desarrollo de sus lugares de origen (Garreta y Guillem, 2010). Según Sanmartín (2011), las dinámicas generadas a partir de las migraciones pueden provocar efectos positivos en el fomento del desarrollo de los lugares de origen de las personas que las protagonizan y generar relaciones más paritarias, con una colaboración mutua y consensuada entre origen y destino. Se recalca la importancia del vínculo y el desarrollo compartido entre las sociedades de origen y destino (Lacomba, 2010) y, en resumen, se enfatiza la idea de que las migraciones internacionales contribuyen al desarrollo, tanto económico como social, cultural y político, de ambas.

Aunque en la mayoría de los casos el codesarrollo es entendido como una forma más de cooperación al desarrollo, se ha defendido que, a diferencia de esta última, el codesarrollo se basa más en la horizontalidad y bidireccionalidad (Giménez et al., 2006). Es decir, no hay un estado receptor y uno emisor de las ayudas, sino que ambos trabajan de forma conjunta a favor de los intereses compartidos, para incidir en el desarrollo humano de forma desterritorializada, tanto en origen como en destino. Para ello, resulta esencial el papel de las personas migrantes como agentes transnacionales $y$, por tanto, como puentes de unión entre las sociedades receptoras y emisoras de migración para llevar a cabo acciones transnacionales de diversa índole, de forma coordinada con los demás actores del desarrollo (Sanmartín, 2010).

Por otro lado, el interés inicial por la vinculación entre migraciones y desarrollo estuvo muy relacionado con las remesas de las personas migrantes, las cuales constituían no solo importantes ingresos en las familias, sino también una fuente esencial de divisas en dichos países (Naïr, 2008). Las remesas han seguido siendo consideradas como un elemento esencial del codesarrollo, debido a que este es concebido mayoritariamente como un fenómeno de carácter económico. En este sentido, mediante el codesarrollo, se ha buscado promulgar el desarrollo de las sociedades de origen partiendo de la premisa de que dicho desarrollo permitirá acabar con la pobreza de estos países y fomentar la estabilidad económica y democrática. En consecuencia, la idea es que el fin de la pobreza reducirá las migraciones del Sur al Norte Globales, pues las personas ya 
no se plantearán la migración como una necesitad (Marín, 2006). Así, «el lema sería dar más cooperación para tener menos inmigración» (Malgesini, 2001: 23).

Esta idea ha ido ganando fuerza con los años y se ha afianzado en las concepciones oficiales del codesarrollo (Aboussi, 2015). La cuestión es que simplificar de este modo la relación entre migraciones y desarrollo no suele dar cuenta de la complejidad de ambos fenómenos (Marín, 2006; Gómez, 2005) y de la ausencia real de relaciones de causalidad directa entre ellos, razón por la cual esta correlación entre el incremento del desarrollo y el descenso de los flujos migratorios defendida por las autoridades políticas ha sido cuestionada en las investigaciones académicas. La disminución de la pobreza no tiene por qué frenar las migraciones, sino que incluso podría llegar a fomentarlas (Marín, 2006). Por ello, a este planteamiento de que a más desarrollo menos migración, podrían sumarse otros que lo desmontarían, como que a mayor migración, mayor desarrollo o incluso que a mayor desarrollo, mayor migración (Lubián, 2012). Parece necesario, pues, desvincular la idea de pobreza y migración (Monsutti, 2008).

Además, esta primera intención de reducir las migraciones a través del desarrollo genera una contradicción, al presentar a las personas migrantes como héroes del desarrollo internacional, a la vez que se concibe el desarrollo como una forma de frenar las migraciones (Monsutti, 2008). Y no solo eso, sino que se interconectan las ideas de «desarrollar para prevenir y reducir la emigración a través de la cooperación [y] generar desarrollo en el país de origen a través de la emigración» (Marín, 2006: 32). Esta concepción de la cooperación al desarrollo como discurso preventivo de las migraciones ha sido la más utilizada, tanto teórica como institucionalmente (Marín, 2006).

\section{1. ¿Cómo organizamos las concepciones del codesarrollo?}

Con todo esto, podemos deducir que el codesarrollo constituye un concepto polisémico, que adopta diferentes definiciones y concepciones y que varía enormemente en función de quién lo emplee. Una primera diferenciación se da entre las prácticas que llevan a cabo las personas migrantes y las acciones o concepciones adoptadas desde las entidades de carácter institucional. Así, varios autores, pese a usar diferentes términos, distinguen entre estos dos tipos de codesarrollo: codesarrollo espontáneo y codesarrollo institucional (Cabezas, 2012); codesarrollo no oficial y codesarrollo oficial (Lacomba, 2012); codesarrollo espontáneo o comunitario y codesarrollo normativo (Lubián, 2012), etcétera. En el presente trabajo, nos limitamos al denominado codesarrollo institucional (empleando el término de Cabezas, 2012) y, más específicamente, el que se plantea desde España como estado receptor de migración (y donante de AOD).

Por otra parte, siguiendo a Lacroix (2009) y a Giménez et al. (2006), al hablar de codesarrollo podemos diferenciar también entre las políticas ofi-

1. Una versión anterior de la propuesta teórica expuesta a continuación fue planteada en una comunicación presentada en el IV Congreso Internacional de Antropología AIBR (Granada, 4-7 de septiembre de 2018). 
ciales ligadas al control de los flujos migratorios y las políticas destinadas a la cooperación al desarrollo. En este sentido, la política de codesarrollo no busca substituir a la política tradicional de cooperación, sino complementarla y otorgarle una nueva dimensión: «La de la gestión de las migraciones al servicio del desarrollo. Dos grandes campos de intervención son privilegiados: 1) la circulación de personas, que debe ser organizada y controlada; 2) la movilización de la inmigración al servicio del desarrollo» (Naïr, 2003: 122).

Pero en esta nueva categorización parecen quedar excluidas las prácticas llevadas a cabo en las sociedades receptoras, por lo que autores como Lacroix (2009), Aboussi (2012) y el propio Naïr (2008), entre otros, propusieron plantear el codesarrollo también como una oportunidad para fomentar la integración de las personas migrantes en dichas sociedades para favorecer la interculturalidad y la convivencia. Con todo esto, podemos plantear una triple concepción del codesarrollo, que se verá reflejada en el análisis expuesto en el siguiente apartado: como instrumento de gestión migratoria, como instrumento de cooperación para el desarrollo y como instrumento de integración.

En primer lugar, desde el discurso predominante, el codesarrollo se define como una manera de gestionar y controlar los flujos migratorios (Giménez et al., 2006; Lacomba y Royo, 2020). Esta es la forma en que fue concebido inicialmente desde la propuesta de Naïr, y que se deriva precisamente de su vínculo con las políticas migratorias europeas. Esto mismo ha ocurrido con la cooperación al desarrollo (Malgesini, 2001; Audran, 2008; Lacomba, 2012; González, 2015). Desde este planteamiento, el codesarrollo permitiría «poder incidir en los países expulsores de población hacia España, como otra medida de gestión migratoria, y de trabajar con aquellos actores institucionalizados, que parecen ser los dotados de legitimidad para actuar en este campo transnacional» (Cortés y Sanmartín, 2010: 197). Así, esta noción es puesta en práctica de dos formas diferentes: como un instrumento de gestión desde cuyas políticas se plantean acciones que regulen los flujos migratorios legales y que restrinjan aquellos de carácter irregular instrumentalizándose y condicionándose las ayudas de la cooperación a estos objetivos (Aboussi, 2015).

En segundo lugar, el codesarrollo es entendido como una tipología más de cooperación al desarrollo (Giménez et al., 2006) cuyo objetivo principal es reducir la pobreza en los países emisores a través de acciones y proyectos de cooperación, pero con la diferencia de que las personas migrantes tienen un papel como agentes activos (Lacomba, 2010). Desde la cooperación, se fomenta el desarrollo en origen para frenar las migraciones fijando a los potenciales migrantes y, a la vez, fomentando el retorno de los ya emigrados (Malgesini, 2001; Audran, 2008). Ello se desprende de la equiparación ya comentada de desarrollo con el crecimiento económico (Sotillo, 2016) y, por tanto, con la idea de que a menos pobreza, menos migraciones.

En tercer y último lugar, desde estas dos conceptualizaciones no se abordan aquellas acciones que, al vincular migraciones y desarrollo, tienen lugar en las sociedades receptoras. Surge aquí el planteamiento del codesarrollo como herramienta de integración. Malgesini (2001) definió este tipo de prácticas 
como de codesarrollo espontáneo, con la afirmación de que el contacto entre diferentes culturas que se genera a partir de la presencia de migrantes tiende a generar efectos que son mutuamente enriquecedores. Por su parte, Crespo (2015) lo denomina codesarrollo intercultural y argumenta que los proyectos, para ser considerados "de codesarrollo", deben llevar a cabo actuaciones en las sociedades receptoras. Así, desde el codesarrollo se implementarían también prácticas que buscan fomentar la convivencia en las sociedades receptoras, a través de una integración de carácter intercultural y un acercamiento mutuo en que los migrantes también ejerzan un papel activo y actúen como «elemento de construcción de ciudadanía en los países de destino» (Aragall, 2010: 283). Sin embargo, tal y como ocurre con las nociones de codesarrollo y desarrollo, el término integración debe ser abordado con cautela, al correr el riesgo de ser empleado como sinónimo de asimilación (Crespo, 2015), en que las personas migrantes deben adaptarse a las sociedades receptoras, sin que se dé un verdadero intercambio y enriquecimiento mutuo.

\section{Breve apunte metodológico}

Para la realización del presente trabajo han sido analizados los principales documentos de la política española de cooperación internacional para el desarrollo. ${ }^{2}$ Para llevar a cabo la revisión de los documentos, y basándonos en el marco proporcionado por la antropología de las políticas públicas (Shore, 2010), ${ }^{3}$ se analizó el modo en que eran abordadas nuestras categorías analíticas: por un lado, el fenómeno migratorio y, por el otro, la noción de codesarrollo. Además, se tuvieron en cuenta aquellas temáticas o ideas que, teóricamente, surgen también en el contexto del vínculo entre migraciones y desarrollo: remesas, gestión migratoria, sociedad de origen, sociedad receptora o de acogida, asociaciones de inmigrantes, retorno, etcétera.

El primer documento abordado ha sido la Ley 23/1998, de 7 de julio, de Cooperación Internacional para el Desarrollo, en la cual se sustenta dicha política. En la Ley 23/1998 se define la cooperación como el

conjunto de recursos y capacidades que España pone a disposición de los países en vías de desarrollo, con el fin de facilitar e impulsar su progreso económico y social, y para contribuir a la erradicación de la pobreza en el mundo en todas sus manifestaciones.

2. Los documentos han sido obtenidos en la página web de la Agencia Española de Cooperación Internacional para el Desarrollo (AECID), <http://www.aecid.es/es/> (último acceso en abril de 2020).

3. Siguiendo a Shore (2010), «el análisis de las políticas públicas implica dar sentido al conocimiento tácito, a las múltiples interpretaciones, y a menudo a las definiciones en conflicto que las políticas tienen para los actores» (p. 23). Estas políticas deben ser entendidas en el contexto sociopolítico e histórico en el que se hallan inmersas, pero sirven también para aprehender los fenómenos que abordan, en este caso, las migraciones y el codesarrollo, y el modo en que lo hacen. 
Se proclama que la política de cooperación internacional constituye un elemento fundamental de la acción exterior del estado, al ser utilizada para relacionarse y llevar a cabo intercambios con otros estados, en este caso, aquellos que, tal y como se establece en la Ley 23/1998, «no han alcanzado el mismo nivel de desarrollo». No hay que olvidar que, en este sentido, la Agencia Española de Cooperación Internacional para el Desarrollo (AECID), principal órgano de gestión de la cooperación, se enmarca en el Ministerio de Asuntos Exteriores y Cooperación (MAEC).

Asimismo, en la Ley 23/1998 se establecen los principales objetivos y prioridades de la cooperación española, así como el conjunto de herramientas y actividades, traducidas en transferencias de recursos públicos materiales y humanos, que la Administración General del Estado destina a los países beneficiarios. Cabe destacar que, "para que dichos recursos tengan la consideración de Ayuda Oficial al Desarrollo (AOD), deberán cumplir los requisitos marcados por el Comité de Ayuda al Desarrollo de la OCDE (CAD)» (Ley 23/1998). $\mathrm{La} \mathrm{AOD}{ }^{4}$ se refiere a las transferencias financieras o técnicas otorgadas por los organismos oficiales de los países donantes, concedidas a los "países socios» u organismos multilaterales de desarrollo.

A partir de la Ley 23/1998, se establecen los planes directores y los planes anuales de la cooperación internacional (PD y PACI, respectivamente), documentos centrales de nuestro análisis. Los primeros son definidos en la Ley 23/1998 como

elemento básico de la planificación de la política española de cooperación internacional para el desarrollo de la Administración General del Estado [que] se formulará cuatrienalmente y contendrá las líneas generales y directrices básicas de la política española de cooperación internacional para el desarrollo, señalando los objetivos y prioridades, así como los recursos presupuestarios indicativos que orientarán la actuación de la cooperación española durante ese período, incorporando los documentos de estrategia relativos a cada sector de la cooperación, zona geográfica y países que sean objeto preferente de la cooperación.

Los PD marcan las directrices a seguir por la cooperación, que se plasman posteriormente en los PACI, y cubren el periodo que va del año 2001 (en que surgió el primer PD) hasta la actualidad. Sin embargo, queremos señalar dos aspectos. Por un lado, que no hemos podido acceder a los PACI a partir del año 2013 (inclusive). De estos años en adelante, solo hemos podido acceder

4. Definición obtenida en la web <http://realidadayuda.org/glossary/ayuda-oficial-al-desarrollo $>$ (último acceso en abril de 2020). Queremos señalar que desde el CAD se propuso incorporar un nuevo código definitorio de la AOD referido a la «facilitación de una migración y movilidad ordenada, segura, regular y responsable», y numerosas entidades de la sociedad civil internacionales lanzaron un comunicado para llamar la atención sobre la peligrosidad de esta iniciativa, al vincular y condicionar las ayudas a un tipo concreto de migración (regular, ordenada), y dejar fuera y criminalizar, de algún modo, cualquier otra forma de movilidad. Se puede consultar el documento en el siguiente enlace: $<$ https://www.dac-csoreferencegroup. com/oda-in-donor-refugee-costs-and-migr> (último acceso en julio de 2021). 
a las comunicaciones de los años 2013,2014, 2015 y, la más reciente, 2019. Por otro lado, entre el IV PD (2013-2016) y el V PD (2018-2021) transcurrió un periodo de dos años en que la cooperación española no contó con PD, pero mantuvo las líneas de actuación del IV hasta la aprobación del actual documento. Un listado de los documentos analizados queda recogido en el cuadro 3 (apartado de Anexos).

\section{Codesarrollo y migraciones en la política española de Cooperación Internacional para el Desarrollo}

A partir del planteamiento teórico expuesto anteriormente, a continuación vamos a analizar la forma en que el codesarrollo es concebido en los planes de cooperación al desarrollo. Sin embargo, antes vamos a centrarnos en el fenómeno migratorio, pues, como afirman Giménez et al. (2006), el codesarrollo surge vinculado irremediablemente a lo migratorio. Por ello, creemos que, para entender cómo se plantea el codesarrollo en esta política y por qué lo hace de esa manera, primero es necesario considerar de qué forma se abordan las migraciones y la realidad de las personas migrantes. Con todo ello, pretendemos vislumbrar el modo en que se erige el vínculo entre migraciones y desarrollo en el ámbito concreto de la cooperación española.

En este sentido, ya en la Ley 23/1998 y en los documentos de planificación que de ella se derivan, se plantea que la cooperación persigue terminar con la pobreza de los países «beneficiarios», con el fin de que estos alcancen el desarrollo económico, social y político deseado. Asimismo, veíamos cómo, en este ámbito, la pobreza es considerada, si no la principal, una de las causas fundamentales de las migraciones. Es por ello que la cooperación se considera una buena herramienta en el campo migratorio, pues siguiendo esta premisa, si se acaba con el subdesarrollo, se frenarán las migraciones. Este es también el pilar básico de los recientes documentos internacionales centrados en el fenómeno migratorio, la Declaración de Nueva York para los Refugiados y los Migrantes - aprobada por la Asamblea General de la Organización de las Naciones Unidas (ONU) en 2016- y el derivado Pacto Mundial para la Migración Segura, Ordenada y Regular — firmado en 2018-, conocido como pacto de Marrakech. Además, veíamos cómo desde la Unión Europea se fomenta el vínculo entre migraciones y desarrollo, sobre todo de cara a la gestión de las primeras, y estas pautas son seguidas por los estados miembros, entre ellos España.

\subsection{El fenómeno migratorio en los documentos de cooperación}

Teniendo en cuenta que la cooperación internacional para el desarrollo se incluye en la política española de asuntos exteriores, podemos comprobar que la forma en que se aborda el fenómeno migratorio en los documentos oficiales de la primera se halla estrechamente vinculada a los planteamientos sobre la migración que priman en cada momento, según los intereses del estado. Es 
por ello que nos llama la atención que en la Ley 23/1998 no se mencione el fenómeno migratorio, cuando este es un elemento esencial para la política de asuntos exteriores, y además partiendo de la consideración de que el fin de la pobreza (objetivo último de la cooperación) puede conllevar una reducción de los flujos migratorios. En este sentido, hay que tener en cuenta que, en el año en el que se aprobó la Ley 23/1998, el fenómeno migratorio no tenía las dimensiones e implicaciones globales que tiene a día de hoy, por lo que no se le otorgaba el peso político y social que ha tenido en años posteriores. Sin embargo, el hecho de que ni siquiera sea mencionado nos resulta, cuando menos, llamativo.

Pese a esto, desde que se empezaron a formular los primeros planes, estos sí que han hecho referencia a esta realidad, con un mayor o menor peso según el momento concreto y abordándola también de forma diferente, lo cual no marca solamente los vínculos migratorios con otros estados (los lugares de salida y tránsito, las rutas, las fronteras y el respeto de los derechos humanos de las personas migrantes en todos ellos), sino también la forma en que serán consideradas y tratadas las personas migrantes en las sociedades receptoras. A grandes rasgos, podemos decir que en los planes de cooperación españoles la migración es concebida como una problemática que hay que abordar desde distintas políticas, una de las cuales es la cooperación, para mejorar la gestión de flujos e intentar reducir la emigración mediante el desarrollo de los lugares de origen de las personas migrantes. Solo en un periodo concreto, donde la cooperación internacional para el desarrollo tuvo también un especial peso en el gobierno de aquel momento, se abordó el papel de las personas migrantes y su contribución en las sociedades receptoras. A continuación, vamos a exponer todas estas cuestiones de forma cronológica, a través del análisis de los PD. En cuanto a los PACI, su análisis no va a ser expuesto de forma pormenorizada, tanto por motivo de espacio como por ser documentos que siguen las mismas líneas y planteamientos que los PD de los que se derivan. Sin embargo, sí que se han tenido en cuenta algunos de sus elementos más relevantes.

En el I PD (2001-2004), se plantea que «en las estrategias de cooperación se incluirán posibles soluciones al fenómeno de la inmigración» (MAE, 2000: 9). Asimismo, el fenómeno migratorio es considerado un elemento clave a tener en cuenta a la hora de definir las prioridades geográficas, lo que muestra los primeros indicios de condicionalidad de la ayuda, cuya distribución entre países y regiones parece estar supeditada al control migratorio. El caso más claro se da en región del Magreb, cuya estabilidad sociopolítica es considerada esencial para España y Europa, por lo que la cooperación debe pasar por la búsqueda de soluciones al "preocupante fenómeno migratorio» (MAE, 2000: 10). El papel de las personas migrantes en los procesos de desarrollo en origen no es contemplado, como tampoco lo es su presencia en la sociedad española. Este PD fue el primero de la cooperación española, y apareció en un contexto sociopolítico liderado por un gobierno de corte conservador, no muy afín a la valoración positiva del fenómeno migratorio, lo cual marcó la forma en que este era concebido. En este periodo surgió también el primer documento estatal 
que planteó el codesarrollo como vínculo entre migraciones y desarrollo, tal como veremos más adelante, pero el cual no se hallaba, de primeras, dentro de la política de cooperación.

El II PD (2005-2008) supuso un profundo cambio en el modo de abordar las migraciones, de forma estrechamente relacionada, a su vez, al cambio en la importancia otorgada a la propia cooperación internacional por parte del gobierno de aquel entonces, más de centroizquierda. La cooperación vivió un importante auge, se buscó su fortalecimiento y puesta en valor, con el compromiso de aumentar la AOD. En este periodo la inmigración es considerada como una fuente de riqueza, tanto para los lugares de origen como para la sociedad receptora, y ya se aborda el papel de las personas migrantes como agentes de desarrollo. Como veremos, cabe destacar que se trata del primer plan donde el codesarrollo es abordado en profundidad. Pese a esto, no se acaba de concretar bien cuál puede ser el papel de las personas migrantes en las sociedades receptoras. Por otra parte, se aboga firmemente por la coherencia entre diferentes políticas asegurando que la ayuda al desarrollo es una política más de las que se establecen de cara a los paises en desarrollo y persiguiendo la erradicación de la pobreza como fin último. Todo ello de forma alineada con el planeamiento de los objetivos de desarrollo del milenio (ODM), donde otras políticas (comercial, económica, empresarial, migratorias, etcétera) pueden tener efectos más intensos que la propia AOD.

En este plan, pese a que no se establece la cuestión migratoria como criterio específico a la hora de definir los países destinatarios de la cooperación, sí se tiene en cuenta a la hora de determinar las acciones a implementar (por ejemplo, en el Magreb y América Latina). Asimismo, la migración es entendida como un fenómeno transnacional, por lo que se apuesta por el trabajo plurinacional, de forma conjunta con instituciones internacionales, donde tiene un papel muy relevante la Unión Europa. Además, se abordan algunas temáticas con independencia de las prioridades geográficas establecidas en el ámbito de país, dado que requieren de un tratamiento que implica a más de un estado. Cabe destacar que este plan apareció antes de la más reciente crisis económica, así como antes de que se dieran importantes sucesos en el plano migratorio que marcarían un antes y después a la hora de concebir las migraciones (por ejemplo, la crisis de los cayucos de Canarias del año 2006).

En el terreno económico, se pretende trabajar sobre el envío de remesas para reducir los costes de las mismas y, en el empresarial, se aboga por el desarrollo empresarial local como una forma de frenar los «innecesarios y dolorosos flujos migratorios» (MAEC, 2005: 77). Así, vemos que en este plan, pese a darse un pequeño cambio en cuanto a la concepción del fenómeno migratorio desde una visión más positiva, sigue considerándose como una cuestión que requiere solución, y la AOD se emplea como fórmula para acabar con la pobreza y, por tanto, reducir los flujos migratorios. Además, la política migratoria es planteada como una forma más de ayuda al desarrollo en los países emisores. Asimismo, como decíamos, los intereses geoestratégicos siguen primando, y el caso más claro es el de América Latina, en que se llega a afirmar que la 
creciente presencia de inmigrantes latinoamericanos en España y de empresas españolas en Latinoamérica supone nuevas oportunidades para la cooperación. En este sentido, el desarrollo del sector privado tiene un gran peso de cara a la persecución de objetivos de desarrollo local y participativo de las poblaciones, al fomentar el emprendimiento como actividad alternativa a la migración.

En el III PD (2009-2012), se consolidan las ideas planteadas en el plan anterior en cuanto a la cuestión migratoria, y se aboga por una política coherente de migraciones y desarrollo. ${ }^{5}$ Como veremos en el siguiente apartado, en este PD se deja de hablar de codesarrollo para hablar del binomio migraciones-desarrollo, y en esta línea se pone en marcha un grupo de trabajo con esta denominación. Para este grupo se pretende contar con la «especial participación de las asociaciones de migrantes» (MAEC, 2009: 92), consideradas agentes clave del desarrollo. Además, se promueven acciones basadas en educación para el desarrollo y dirigidas a la sensibilización respecto a temáticas como la inmigración, con un gran peso otorgado a la cooperación en el ámbito local (descentralizada).

Por otro lado, en línea con los documentos anteriores, también se abordan las remesas como elemento esencial y se busca poner freno a la fuga de cerebros a través de distintas medidas, una de las cuales es la cooperación. En este PD, migración-desarrollo es elevado a prioridad sectorial de la cooperación, en que destaca la importancia de las migraciones en el escenario transnacional, y cuyo efecto esperado se centra en

fomentar los efectos positivos recíprocos entre migración y desarrollo, a través de la promoción del codesarrollo, empoderamiento de las diásporas y el apoyo a la elaboración y puesta en práctica de políticas públicas de migración adecuadas y coherentes, en los países de origen, tránsito y destino protegiendo los derechos de las personas migrantes en todas las fases del proceso (MAEC, 2009: 53).

Asimismo, aunque aseguran que la pobreza y la falta de oportunidades pueden ser una de las razones que llevan a las personas a emigrar, también se señala que la lucha contra la pobreza no tiene una relación de causalidad inmediata con el fenómeno migratorio, por lo que, a su vez, «los vínculos entre la migración y el desarrollo responden a una relación de interdependencia compleja, en la que es imprescindible trabajar en un plano integral y multidimensional» (MAEC, 2009: 174). La lucha contra la pobreza se persigue como un fin en sí mismo, no

5. Resulta interesante señalar que en los PACI, a partir de 2009, el interés por las migraciones empieza a decaer, y las aproximaciones al fenómeno se limitan a aspectos puntuales, como las remesas o el potencial del retorno. En comunicaciones posteriores de los últimos planes, las menciones al fenómeno migratorio son casi existentes. Tampoco aparece reflejado en los planes estratégicos de ese periodo, como es el caso del PE (2014-2017).

Por otra parte, cabe destacar que a partir de 2008, con la crisis económica, la inmigración recibida por España, creciente hasta el momento, se estanca e incluso empieza a disminuir, lo que afecta así al lugar ocupado por el fenómeno migratorio en la esfera política y social (Gozálvez, 2012). 
supeditado a ningún otro, y constituye parte esencial de la política exterior del Estado español. En este mismo sentido, se dice que las políticas de desarrollo no tienen como fin directo actuar sobre los flujos migratorios, sino que buscan generar oportunidades y expectativas en los países de origen, por lo que la política de cooperación en materia migratoria tiene sus propios indicadores de desarrollo y la AOD no debe orientarse a actividades de control de flujos.

Así, en este plan, la política de cooperación se desliga del discurso preventivo que suele primar en el ámbito institucional. Se afirma que desde la cooperación española, y de forma enmarcada en el respeto a los derechos humanos y la promoción de la ciudadanía global, se busca contribuir, integradamente, a la adecuada gestión migratoria y al favorecimiento de las oportunidades de las personas migrantes, todo ello en origen, tránsito y destino. Aun así, se pretende mantener la coherencia de políticas y coordinación multilateral en materia migratoria con los demás ministerios (como el Ministerio de Trabajo y el Ministerio del Interior), y también con el origen y los países de tránsito, y con las políticas migratorias, educativas, culturales, sanitarias, etcétera. «Del mismo modo, el apoyo a la construcción en los países de origen y tránsito de estas políticas migratorias también ha de integrarse en las políticas de cooperación internacional impulsadas por parte de países desarrollados y organismos internacionales» (MAEC, 2009: 174).

En el IV PD (2013-2016), la forma de abordar el fenómeno migratorio cambia de nuevo y radicalmente, ya que pasa casi inadvertido y pierde la valoración anteriormente otorgada como fuente de riqueza. También se pierde de vista el posible aporte de las personas migrantes a las sociedades receptoras, y se aboga por un discurso centrado en el potencial de las remesas y el retorno. La inmigración es presentada de nuevo como un desafío global. Estos cambios en la política de cooperación fueron de la mano de los cambios políticos vividos en el Estado español (al volver de nuevo al gobierno del primer plan), así como por el fuerte impacto de la crisis económica y de la aparición de fenómenos tan relevantes como la crisis de refugiados. En este sentido, el interés por la cooperación disminuyó y se redujo enormemente el gasto destinado a AOD. Esto fue consecuencia no solo de los recortes sufridos en el gasto público por la crisis económica, sino también por la falta de interés de cara a la propia cooperación al desarrollo —uno de los sectores más afectados por dichos recortes_-, con un papel clave, asimismo, de otros aspectos de carácter ideológico.

Así, en este PD se afirma que «España atraviesa tiempos difíciles que obligan a reducir el gasto público, incluido el de cooperación, al tiempo que nos imponen una mayor eficiencia y una correcta priorización en la asignación de nuestros recursos» (MAEC, 2013: 3). Para ello, la cooperación se centró en aquellas áreas donde España tenía mayores intereses geoestratégicos. Esta cuestión, pese a darse de forma implícita en los demás PD, aparece explícitamente expresada en este, lo cual deja claro los planteamientos subyacentes a estas políticas de supuesta ayuda, en que, en lugar de priorizarse la cooperación con los países que más la necesitan, estos se seleccionan según los intereses del estado donante, en este caso España. Retomando la cuestión migratoria, se sigue abo- 
gando por otros flujos económicos de mayor calado: el comercio, la inversión y, sobre todo, las remesas, tal y como ocurría en los documentos anteriores. Se recalca que «los Gobiernos no somos ya los únicos actores. La sociedad civil, el sector privado y los propios individuos juegan un papel protagonista» (MAEC, 2013: 3), de modo que se otorga ciertas responsabilidades a la población local, pero sin incidir específicamente en el rol de las personas migrantes.

Por último, como hemos adelantado, el V PD (2018-2021) no fue aprobado hasta 2018, por lo que hubo un periodo de casi tres años en que la cooperación no contó con un plan director. Además, fue aprobado pese a las amplias resistencias de la mayoría de actores. El V PD cubre el periodo que va de 2018 a 2021, y en él se siguen las líneas de la Agenda 2030 y los consecuentes objetivos de desarrollo del milenio (ODS), ${ }^{6}$ en sus componentes de cooperación internacional. En este sentido, en el ODS 10, Reducción de las desigualdades, la meta 7 se centra en «facilitar la migración y la movilidad ordenadas, seguras regulares y responsables de las personas, incluso mediante la aplicación de políticas migratorias planificadas y bien gestionadas» (MAEC, 2018: 34), por lo que se trabajará en capacitar a las instituciones para promover la migración ordenada aplicando el enfoque de derechos humanos y de seguridad de las personas. Asimismo, en línea con el ODS 16, centrado en Paz, justica e instituciones sólidas, también se busca "dar una solución permanente a las causas que están en el origen de los grandes flujos migratorios» (MAEC, 2018: 37).

En el V PD la migración es abordada como uno de los fenómenos de mayor impacto social y político y, de nuevo, como un reto de la cooperación y «de la comunidad internacional en su conjunto» (MAEC, 2018: 6). En línea con documentos internacionales como el Pacto de Marrakech, se apuesta por una migración ordenada, regular, segura y legal, que pueda reportar beneficios a las sociedades de origen y destino y a las personas migrantes. Se aboga por trabajar sobre las causas profundas de las migraciones buscando soluciones duraderas mediante programas en las regiones de origen que incrementen sus capacidades de gestión de flujos y control de fronteras, y retomando para tal fin la temática de migración y desarrollo. Así, se mantiene el discurso de los primeros planes y documentos, en que se consideraba que las migraciones eran un reto de la cooperación, y se ponía énfasis en la prevención y la lucha contra la migración ilegal, a la vez que, paradójicamente, se busca apoyar la libre circulación de personas. A modo de resumen, y citando el propio plan,

los grandes movimientos de población y los flujos migratorios son uno de los fenómenos de mayor impacto, político, social, en opinión pública, de los últimos años. La migración, adecuadamente regulada y realizada con seguridad, puede contribuir al crecimiento inclusivo y el desarrollo sostenible, y reportar beneficios a las personas migrantes, a los países receptores y a los de origen. Los nuevos trabajadores aportan en los sistemas fiscales de los países receptores, y mediante los flujos de remesas apoyan a las familias que dejan en sus países.

6. Los ODS pueden consultarse en la página web de las Naciones Unidas, en el siguiente enlace: <http://www.un.org/sustainabledevelopment/es/> (último acceso en abril de 2020). 
Además, las remesas inteligentes o los migrantes que invierten y ejercen actividades profesionales o sociales en sus países de origen ponen de manifiesto el papel de la diáspora como motor del desarrollo en los países de origen, incidiendo en las raíces profundas que provocan esa migración y ofreciendo soluciones duraderas a los problemas. (MAEC, 2018: 9)

Como resumen, en el siguiente cuadro se plasman las principales cuestiones de cada periodo, en lo que respecta al modo en que los documentos analizados abordan el fenómeno migratorio.

Cuadro 1. El fenómeno migratorio en la política de cooperación internacional para el desarrollo

\begin{tabular}{|c|c|}
\hline Periodo & Cuestiones principales \\
\hline \multirow[t]{3}{*}{$2001-2004$} & Migración como problemática a abordar desde la cooperación \\
\hline & Gestión migratoria y discurso preventivo \\
\hline & Impacto de remesas y retorno \\
\hline \multirow[t]{4}{*}{$2005-2008$} & Valorización positiva del fenómeno migratorio \\
\hline & Migrantes como agentes de desarrollo \\
\hline & Coherencia de políticas y reducción de la pobreza \\
\hline & Potencial de remesas \\
\hline \multirow[t]{6}{*}{$2009-2012$} & Binomio migraciones-desarrollo (prioridad sectorial) \\
\hline & Migración como riqueza sociocultural \\
\hline & Migrantes como agentes de desarrollo \\
\hline & Coherencia de políticas \\
\hline & Educación para el desarrollo \\
\hline & Potencial de remesas \\
\hline \multirow[t]{3}{*}{ 2013-2016 } & Migración como desafío global \\
\hline & Potencial de remesas y retorno \\
\hline & Priorización explícita de intereses geoestratégicos \\
\hline \multirow[t]{3}{*}{$2018-2021$} & Migración como desafío \\
\hline & Gestión migratoria y discurso preventivo \\
\hline & Causas profundas de las migraciones \\
\hline
\end{tabular}

Fuente: elaboración propia a partir del análisis documental.

\subsection{El codesarrollo en los documentos de cooperación}

Como se ha podido deducir del apartado anterior, España quiso convertirse en un referente en las nuevas políticas que vinculaban migración y desarrollo (Lacomba, 2010). Distintos agentes, incluyendo entidades gubernamentales, tanto del ámbito estatal como autonómico, y entidades no gubernamentales o de la sociedad civil, como ONG y las propias asociaciones de migrantes, empezaron a percibir el codesarrollo como una buena estrategia para implicar 
a las personas migrantes en el desarrollo de sus lugares de origen. Sin embargo, la participación no ha sido la misma por parte de los diferentes agentes, con distintos grados de interés e implicación con el paso de los años, y con la impresión de que no se terminaba de dar una sinergia adecuada entre los responsables de la cooperación y de inmigración (Giménez, 2010).

Como anunciábamos, el primer documento en que aparece reflejado el codesarrollo fue el Programa Global de Regulación y Coordinación de la Extranjería y la Inmigración (en adelante, Plan GRECO) en el año 2001 (Giménez et al., 2006), el cual no se enmarcaba en la política de cooperación, pese a tener gran influencia en la forma en que esta abordaría posteriormente el codesarrollo. En este plan se marcan las directrices para la política migratoria, orientadas a la gestión de los flujos y la prevención de aquellos que tienen carácter irregular, así como al retorno de las personas migrantes, según las líneas marcadas por el Consejo Europeo de Tampere. Las premisas que dirigen este planteamiento se centran en que «el incremento de la cooperación al desarrollo, ahora rebautizada codesarrollo cuando se aplica a países de los que proceden los inmigrantes, permitirá fijar a la población en origen» (Malgesini, 2001: 132). Según se establece en el propio documento, este plan de carácter cuatrienal «representa la primera iniciativa en nuestro país para afrontar el tratamiento de la extranjería y la inmigración desde todas sus vertientes, partiendo de la trascendencia e importancia [de] este fenómeno». En este documento, la migración es abordada de forma transversal, y se plantean medidas de cara tanto a la gestión migratoria como a la integración de las personas migrantes en las sociedades receptoras. Para ello, «se parte de la importancia de las actuaciones en los países de origen y tránsito de inmigración, así como de la política europea de inmigración y asilo».

Siguiendo esta línea, en el primero de los objetivos propuestos en el plan, a saber, el «diseño global y coordinado de la inmigración como fenómeno deseable para España en el marco de la Unión Europea», una de las medidas a adoptar se concreta en el «codesarrollo de los países de origen y tránsito de los inmigrantes». Así, aparece por primera vez este fenómeno, pero en ningún punto del plan se ofrece una definición del mismo, más allá de concebirlo como el «desarrollo compartido por los sujetos participantes». En cuanto a este planteamiento, se afirma que

la inversión para el codesarrollo de los países de emigración tiene que ser la pieza clave del diseño global de la política del Gobierno en la presente legislatura, en la que hemos de favorecer, entre otras actuaciones, el retorno de emigrantes a sus países de origen. Su mejor formación profesional después del trabajo desarrollado aquí será un valor añadido a su propio bagaje, que les permitirá contribuir al esfuerzo de desarrollo y crecimiento de sus propios países.

Así, vemos cómo aparecen algunas nociones clave que posteriormente se verán reflejadas, también, en la política de cooperación al desarrollo, a la hora de incorporar el discurso del codesarrollo. Destaca, sobre todo, el fomentar el 
retorno como una forma de desarrollar sus lugares de origen. Para lograr este objetivo, algunas de las medidas propuestas son las siguientes: la formación de las personas inmigrantes como agentes de desarrollo a su regreso a los países de origen - es en este punto donde, según el documento, se "pretende unir las políticas de inmigración con las de cooperación para el desarrollo»—; ayudar a su reinserción en los lugares de origen facilitando el retorno y el reasentamiento-; orientar el ahorro y las remesas de las personas migrantes hacia inversiones productivas que contribuyan al desarrollo o crecimiento económico en las regiones de origen - según este planteamiento, «las inversiones en las zonas de presión migratoria han de ayudar a la canalización de los flujos migratorios hacia los países de origen»—, y finalmente la concesión de microcréditos orientados a proyectos de desarrollo social y la asistencia técnica a los países de procedencia de las personas inmigrantes. Para implementar todas estas medidas, se apuesta por contar con diversos órganos responsables, entre ellos el Ministerio de Trabajo y Asuntos Sociales, la Delegación de Ordenación de las Migraciones, SECIPI y la AECI (por aquel entonces, todavía no AECID). Con todo esto, con el Plan GRECO se buscó vincular las políticas migratorias con las de cooperación al desarrollo, para marcar el camino que se seguiría años después y condicionar la AOD a los intereses geoestratégicos y migratorios de España.

En cuanto a la política de cooperación, al abordar el fenómeno migratorio, ya se han comentado algunos elementos referentes al codesarrollo. En primer lugar, al igual que ocurría con el fenómeno migratorio, en la Ley 23/1998 no se hace ninguna referencia al codesarrollo, lo cual puede resultar llamativo si tenemos en cuenta que el año anterior a su instauración fue precisamente cuando Naïr publicó el informe popularizando este asunto. En cuanto a los planes de cooperación, habría que esperar hasta el II PD para que el codesarrollo fuera abordado, aunque en este plan echamos de menos una definición clara acerca de qué entiende la cooperación española por codesarrollo. Sin embargo, cabe destacar que en el I PD, pese a no hacerse mención expresa al término de codesarrollo ni al binomio migraciones-desarrollo, como veíamos, la cooperación sí que es concebida como una herramienta que puede servir para afrontar el problema de la inmigración. El I PD y el Plan GRECO aparecieron de forma más o menos simultánea, por lo que la incorporación del codesarrollo en el discurso de la cooperación se daría en el PD siguiente y también apareció por vez primera en el PACI 2004. Aunque, como ocurrió también con el fenómeno migratorio, el codesarrollo se plasmó con un enfoque distinto, menos restrictivo, poniendo en valor los aspectos positivos de la migración y la presencia de personas migrantes en la sociedad española.

Así, en el II PD, el codesarrollo ocupa un punto completo en el apartado de coherencia de políticas, dentro del bloque dedicado a la calidad de la ayuda. El codesarrollo es considerado uno de los tres «asuntos que más relevancia tienen en el sistema de cooperación español, con el propósito de avanzar en la coherencia con el objetivo del desarrollo» (MAEC, 2005: 114). Asimismo, aparece reflejado también en otro punto del mismo apartado, el 2.1, 
destinado a la «especial consideración de la política multilateral, la cooperación reembolsable, los esquemas de condonación de deuda y codesarrollo en la coherencia de políticas» (MAEC, 2005: 117). Tal y como se planteaba en el Plan GRECO, se afirma que "la política de codesarrollo se ejecutará en coherencia con las políticas definidas desde el Ministerio de Trabajo y Asuntos Sociales y, específicamente, desde la Secretaría de Estado de Inmigración y Emigración, en coordinación con otras administraciones y agentes de la cooperación» (MAEC, 2005: 120). De igual modo, se busca establecer un modelo multilateral de codesarrollo basado en la riqueza aportada por los flujos migratorios como fenómeno multicultural y transnacional, contando con la representación de diversos actores y enlazando con experiencias internacionales. Además, se afirma que la cooperación española priorizará inicialmente las acciones de codesarrollo en Marruecos y Ecuador, como consecuencia del alto volumen de inmigrantes de estas procedencias que habitaban en el Estado español por aquel entonces.

Para lograr los propósitos respecto a la cuestión del codesarrollo, en el punto destinado al mismo se plantean las seis líneas de actuación siguientes:

a. Consideración de los flujos migratorios, tanto desde el punto de vista cuantitativo como cualitativo, a efectos de priorizar regiones, zonas o países y de establecer las estrategias de codesarrollo.

b. Fomento del desarrollo en origen mediante la promoción económica, el apoyo a la pequeña empresa y el fortalecimiento de los sectores productivos.

c. Impulso a la participación de las personas inmigrantes en estrategias de codesarrollo, en coordinación con asociaciones de inmigrantes en España y agentes de cooperación, como vía para el fomento de la integración.

d. Implicación de las personas inmigrantes como agentes de desarrollo y contribuyentes al avance social, económico y cultural de sus países de origen.

$e$. Diseño de un modelo de retorno digno y sostenible, que incluya medidas de capacitación profesional y empresarial, apoyo económico (microcréditos $\mathrm{u}$ otros instrumentos financieros) y orientaciones sobre la viabilidad de las iniciativas socioproductivas que se propongan para desarrollar en los países de origen.

f. Impulso de actuaciones sobre utilización racional de remesas, canalización de los envíos de divisas y productos financieros favorables, fomentando las iniciativas de información y asesoramiento a los inmigrantes en este ámbito. (MAEC, 2005: 120)

Así, vemos cómo el codesarrollo es planteado como una herramienta que va a permitir fomentar el desarrollo de los lugares de origen mediante la participación de las personas migrantes como agentes de desarrollo. Pese a que este es considerado en gran medida desde una aproximación económica —al equipararse al crecimiento y buscar canalizar las actuaciones, retorno y remesas de las personas migrantes hacia la inversión productiva y económica-, también se introduce como nueva perspectiva la implicación de las personas 
migrantes y sus asociaciones en el fomento de la integración en las sociedades receptoras, cuestión no abordada hasta el momento. De este modo, se pretende impulsar la participación de las personas migrantes en dos sentidos: por un lado, como agentes de desarrollo y como contribuyentes al avance social, cultural y económico de sus lugares de origen y, por el otro, como agentes en proyectos de cooperación en la sociedad española que fomenten la convivencia. En los PACI, el codesarrollo vive un fuerte impulso a partir del 2006 - en años posteriores se destacan los logros obtenidos en esa fecha-, y se sigue manteniendo la voluntad de vincular migraciones y desarrollo dando un peso importante a las remesas, la implicación de las personas migrantes y la necesaria coordinación entre agentes

En el III PD, en el efecto esperado en cuanto a migraciones y desarrollo, veíamos como se hacía mención a la promoción del codesarrollo y se consolidaban las ideas y propuestas del plan anterior: fomentar los efectos positivos recíprocos entre migraciones y desarrollo potenciando los efectos económicos del fenómeno migratorio sobre el desarrollo; actuar en las sociedades de origen, tránsito y destino; contar con las personas migrantes como agentes de desarrollo y vínculo transnacional entre sus lugares de origen y la sociedad receptora, y favorecer su participación en estas políticas de forma conjunta con otros autores de la cooperación, etcétera. Las asociaciones de migrantes y las diásporas adquieren un importante rol como motores de desarrollo y cambio social, con un potencial protagonismo en los procesos de codesarrollo. Sin embargo, cabe destacar que este plan no se centra tanto en el codesarrollo en sí, sino en el binomio migraciones-desarrollo, considerado prioridad sectorial, y con referencia al codesarrollo en las líneas estratégicas y actuaciones a seguir dentro de esta línea.

En este sentido, en 2008, desde la Secretaría de Estado de Cooperación Internacional, se creó un documento que recogía las principales líneas de actuación en migración y desarrollo (MAEC, 2008). En este documento, el codesarrollo es concebido como un ámbito aplicado de este campo, a través del apoyo y la puesta en marcha de programas y proyectos en estas áreas, y mediante el diseño de políticas públicas destinadas a estimular la contribución de las diásporas y asociaciones de migrantes en sus países de origen. Se recalca también la necesidad de abordar estrategias de desarrollo amplias que incidan en las causas de los flujos migratorios, pese a que no se considera que la lucha contra la pobreza y el fenómeno migratorio tengan una relación de causalidad inmediata. Esta idea, como veíamos en el apartado anterior, se presenta también en el II PD, pues ambos comparten líneas estratégicas y planteamientos, ya que en ocasiones aparece el mismo texto en los dos documentos. Finalmente, en este documento se aboga por abordar estrategias concretas a corto y medio plazo, de cara a apoyar a los países de origen y tránsito en la elaboración y puesta en práctica de políticas públicas para la gestión adecuada de los flujos migratorios. Estas políticas deberían ir enfocadas a maximizar los efectos positivos, tanto para los estados como para las personas migrantes, pues en el texto se afirma que, pese a que la primera responsabilidad en esta materia reside en 
los países de destino, se debe contar también con la implicación de los países de origen y tránsito.

Siguiendo este mismo planteamiento, en el III PD, el efecto esperado en el sector Migraciones y desarrollo se establece en su objetivo general (OG):

Fomentar los efectos positivos recíprocos entre migración y desarrollo, a través de la promoción del codesarrollo, empoderamiento de las diásporas y el apoyo a la elaboración y puesta en práctica de políticas públicas de migración adecuadas y coherentes, en los países de origen, tránsito y destino protegiendo los derechos de las personas migrantes en todas las fases del proceso. (MAEC, 2009: 176)

Este OG se concreta en cinco objetivos específicos que pasan por apoyar a los países de origen y tránsito en el establecimiento de mecanismos de gestión e información en materia migratoria para maximizar sus efectos positivos; promover espacios de diálogo y coordinación en la acción conjunta de migraciones y desarrollo con diferentes agentes, incluyendo las asociaciones de migrantes y las organizaciones de la sociedad civil, tanto en origen como en destino; e impulsar la coherencia de políticas, tal y como se planteaba en documentos anteriores. Es entre las líneas propuestas para lograr estos objetivos donde aparece reflejada la noción de codesarrollo: «Promocionar las iniciativas de codesarrollo y la participación concertada en las mismas de una pluralidad de actores (asociaciones de migrantes, sector público, sector privado y organizaciones de la sociedad civil tanto en los países de origen como en España)» (MAEC, 2009: 176). A lo largo de las propuestas, las asociaciones de migrantes y diásporas son consideradas agentes de desarrollo y de cambio social, ya que potencian los lazos con las sociedades de origen y su implicación en iniciativas de codesarrollo. Todo ello se produce a través del «apoyo a la creación y refuerzo de los espacios de consulta y participación de todos los actores implicados [...] en el diseño, elaboración, aplicación, seguimiento y evaluación de las políticas públicas de migración y desarrollo» (MAEC, 2009: 177).

Con todo esto, y en resumen, el II y el III PD se caracterizaron por la puesta en valor del codesarrollo y la consideración del fenómeno migratorio y las propias personas migrantes como elementos clave de los procesos de desarrollo, tanto en origen como en destino, lo que favorece su beneficio mutuo, en línea con las propuestas orientadas a la aplicación del codesarrollo en el ámbito de la cooperación al desarrollo. Sin embargo, en el IV y V PD, el codesarrollo desaparece por completo, se obvia la participación de las personas migrantes y se retoma un enfoque de la cooperación como herramienta de gestión de las migraciones. En este sentido, se hace una breve mención al área de migraciones y desarrollo, pero sin concretar nada al respecto. Veíamos también cómo en este último plan se consideraba de nuevo la migración como una problemática a abordar desde la cooperación al desarrollo. La misma evolución se vivió en los PACI, pero de forma más temprana. Aunque en el PACI 2009 se sigue abogando por promover los efectos positivos recíprocos entre el fenómeno migratorio y el desarrollo, en el PACI 2010 este interés por el codesarrollo desaparece y no se le dedica ningún apartado ni punto concreto. Tampoco es mencionado 
en ninguno de los planes ni comunicaciones posteriores, incluyendo la más reciente de 2019.

Finalmente, en el siguiente cuadro resumimos las principales cuestiones surgidas al analizar el modo en que los documentos de la política de cooperación abordan el fenómeno del codesarrollo. Como podemos comprobar, las líneas planteadas corren parejas a las cuestiones que se vislumbraron también en el apartado anterior, lo que pone de relieve la fuerza del vínculo entre migraciones y codesarrollo en el ámbito de la cooperación al desarrollo.

Cuadro 2. El codesarrollo en la política de cooperación internacional para el desarrollo

\begin{tabular}{ll}
\hline $2001-2004$ & No consta \\
\hline Periodo & Cuestiones principales \\
\hline $2005-2008$ & Codesarrollo como elemento central en la coherencia de políticas \\
& Codesarrollo como elemento central en la calidad de la ayuda \\
& Modelo multilateral del codesarrollo \\
& Fomento del desarrollo en origen \\
& Migrantes como agentes de desarrollo \\
& Puesta en valor del codesarrollo \\
\hline $2009-2012$ & Codesarrollo como efecto del binomio migraciones-desarrollo \\
& Asociaciones de migrantes y diáspora \\
& Causas profundas de las migraciones \\
& Migrantes como agentes de desarrollo \\
& Puesta en valor del codesarrollo \\
\hline $2013-2016$ & No consta \\
\hline
\end{tabular}

Fuente: elaboración propia a partir del análisis documental.

\section{A modo de conclusión}

A lo largo de este recorrido por los planes de la política española de cooperación internacional para el desarrollo, hemos podido ser testigos del modo en que el discurso institucional del codesarrollo ha ido evolucionando a lo largo de los años, en consonancia con los cambios políticos, económicos y sociales del Estado español. En este contexto, este se erige como receptor de los flujos migratorios procedentes del Sur Global, a la vez que como país donante de AOD en materia de cooperación al desarrollo. Hemos visto cómo la migración suele ser presentada como un desafío social que es posible abordar desde la cooperación al desarrollo basándose en la premisa de que el desarrollo económico y social de los lugares de origen frenará la necesidad o la voluntad de emigrar de estas personas. También hemos podido observar que se ha intentado fomentar el retorno de los migrantes a través de la cooperación, por lo que las concepciones prioritarias del codesarrollo han funcionado como 
herramienta de cooperación al desarrollo y como instrumento vinculado a la gestión de flujos.

Por otro lado, destaca un periodo concreto en que, como hemos visto, se defiende el papel de las personas migrantes como agentes de desarrollo no solo de los lugares de origen, sino también de las sociedades de destino. Esta voluntad de implicar a las personas migrantes como actores principales del codesarrollo, en coordinación con los demás agentes, supuso un cambio de perspectiva que no se mantuvo con el paso de los años. Sin embargo, cuando sí se las tuvo en cuenta, su participación se entendía como esencial no solo para promover el desarrollo en origen (aunque los planes suelen centrarse en este aspecto), sino para favorecer la integración en destino fomentando la creación de sociedades interculturales. En este sentido, queremos destacar que el codesarrollo sí que aparece planteado en los Planes Estratégicos de Ciudadanía e Integración (PECI, en sus ediciones de 2007-2010 y 2011-2014), en los periodos en que desapareció de los planes de cooperación.

Con todo ello, podemos ver que, en cierto modo, el codesarrollo es concebido según las tres concepciones teóricas planteadas. Primero, en los primeros documentos y en los últimos se hace hincapié, sobre todo, en el enfoque preventivo de las migraciones empleando el codesarrollo (y la cooperación) como una herramienta para tal fin. Este planteamiento se mantiene a lo largo de los demás documentos, aunque de manera más sutil. Segundo, el codesarrollo es entendido también - y sobre todo- como herramienta de cooperación al desarrollo, aunque esta concepción se debe a que, precisamente, este es el ámbito desde el que se ha realizado la investigación, al analizar los documentos de esta política de forma específica. Además, en muchos casos ambas concepciones aparecen estrechamente entrelazadas, por lo que resulta complejo separarlas. Lo mismo ocurría con los apartados del presente trabajo destinados a abordar, por un lado, las migraciones y, por el otro, el codesarrollo. Ello se debe a que, al fin y al cabo, se presentan de forma conjunta en los documentos, al ser el codesarrollo, precisamente, la forma en que se concibe el vínculo entre cooperación y migraciones (estas aparecen en mayor medida que el propio concepto de codesarrollo). Finalmente, veíamos cómo en un momento puntual también se aborda el posible rol de las personas migrantes, sus asociaciones y diásporas en la puesta en marcha de acciones orientadas a la integración y convivencia en las sociedades receptoras, para aproximarse así a la tercera conceptualización planteada del codesarrollo.

Por otra parte, hay que tener en cuenta que, pese a que desde los planes se marque el rumbo a seguir en la política de cooperación, al final la puesta en práctica de todos estos procesos puede diferir de su planteamiento, al adaptarse a las necesidades de cada momento y a las decisiones tomadas por los diferentes agentes implicados, quienes, en ocasiones, pueden no ver plasmadas sus necesidades reales en los documentos oficiales. Asimismo, las medidas propuestas desde los planes, por muy beneficiosas que puedan parecer, no pueden verse materializadas si no se les destinan los recursos económicos, técnicos y materiales que requieren de cara a su implementación. Los recortes en 
la financiación que se han dado en la cooperación internacional al desarrollo afectan a la puesta en marcha y materialización de las acciones propuestas en distintos ámbitos, y uno de ellos es el codesarrollo. Todo esto sin olvidar que la propia cooperación vive sumergida en un cuestionamiento constante -que la persigue desde hace décadas_-, que precisa de una profunda reflexión acerca de hasta qué punto sus objetivos siguen siendo lícitos y si se adaptan a las necesidades reales de las complejas sociedades actuales y, sobre todo, de las personas que deberían verse beneficiadas por la misma. Pero este debate escapa a los objetivos de este trabajo.

La cooperación al desarrollo y el codesarrollo no pueden escapar del contexto en el que son pensados, concebidos y definidos. En el ámbito institucional de las sociedades receptoras, estas realidades se vinculan al fenómeno migratorio, el cual pasa a ser abordado de manera diferente según el momento concreto, pero primándose un discurso de carácter preventivo, en el que se busca frenar la emigración mediante el desarrollo de los lugares de origen y fomentar también el retorno de los emigrados. El vocabulario empleado puede decir mucho de las ideas que sustentan un discurso. Así, en los planes hemos visto que términos como riqueza, beneficio mutuo, corresponsabilidad y participación contrastan con otros como control, fronteras, regular e ilegal, lo que hace que, pese a que se destacan aspectos positivos de la inmigración, en el trasfondo se detecte un discurso de marcado signo negativo, que además es el mismo que suele plantearse desde los poderes públicos y los medios de comunicación. A modo de apunte, otros términos sobre los que nos ha parecido interesante detenernos se refieren al uso, de forma indistinta, de los conceptos de sociedad receptora y sociedad de acogida. Esta última noción tiene un cariz relevante debido a que, en ocasiones, las personas migrantes sufren situaciones de discriminación, racismo y exclusión que hacen que las sociedades en las que se asientan, en el Norte Global, no sean tan acogedoras como se promulga en los documentos oficiales.

Por otro lado, parecería que muchas acciones llevadas a cabo en el marco de la cooperación institucional acaban siendo catalogadas como de codesarrollo por el mero hecho de contar con la presencia (que no siempre participación) de las personas migrantes, pero no acaba de concretarse realmente qué es lo que se pretende, ni si estas son las prácticas que se quieren llevar a cabo o si responden a las necesidades planteadas y manifestadas por estas personas. Es por ello que tal vez el codesarrollo institucional deba trabajar de forma más próxima a las acciones adoptadas por las personas migrantes, sus asociaciones y las diásporas, y seguir los planteamientos propuestos tanto de cara a su integración en destino como a las acciones de desarrollo respecto a sus lugares de origen. No por etiquetarlas como acciones de codesarrollo se beneficia a las personas migrantes, ni se respeta la horizontalidad entre sociedad receptora y sociedad de origen. Cuando sí se den estos elementos, puede resultar interesante abordar el codesarrollo de forma transversal en los diferentes proyectos, tanto de cooperación como de acción social (Herrero de Egaña, 2012). De todas formas, primero, habrá que acabar de explicar qué entendemos por codesarrollo y 
cómo queremos que sea realmente ese vínculo entre migraciones y desarrollo. Para ello, puede resultar esclarecedor (y, cuando menos, pertinente) comparar el discurso institucional analizado en este trabajo con las prácticas sobre el terreno y las realizadas por las personas migrantes. Así se podrá comprobar si se confirman, revierten o contradicen los planteamientos oficiales e intentar dar una respuesta al debate en torno al codesarrollo, que todavía permanece abierto, y que puede volver a ocupar un lugar relevante en los estudios sobre migraciones y desarrollo.

\section{Agradecimientos}

Este trabajo se enmarca en la investigación de tesis doctoral en curso. $\mathrm{Su}$ autora es beneficiaria de un contrato FPU (16/03409), en el marco del Programa de Doctorado en Estudios Migratorios de la Universidad de Granada (UGR). Agradece a sus compañeras del programa, así como a su director y a su codirectora de tesis, todas las aportaciones y revisiones realizadas al presente texto.

\section{Referencias bibliográficas}

Авоussi, Mourad (2012). El codesarrollo ante los retos actuales del transnacionalismo, gobernanza y ciudadania: aplicaciones al caso hispano-marroqui. Tesis doctoral. Granada: Universidad de Granada.

- (2015). «Codesarrollo institucional versus codesarrollo académico: enfoques preventivos, politizados e idealistas de una idea con potenciales de desarrollo compartido». En: García, F. Javier; Megías, Adelaida y Ortega, Jennifer (eds.). Actas del VIII Congreso sobre Migraciones Internacionales en España (Granada, 16-18 de septiembre de 2015). Granada: Instituto de Migraciones.

Aragall, Xavier (2010). «I Congreso Internacional de Codesarrollo. Conclusiones». En: SolÉ, Carlota (coord.). Migraciones y desarrollo. El codesarrollo: del discurso a la práctica. Barcelona: Anthropos.

Audran, Jérôme (2008). «Gestion des flux migratoires: réflexions sur la politique française de codéveloppement». Annuaire Suisse de Politique de Développement, 27 (2), 101-113. <https://doi.org/10.4000/aspd.187>

Cabezas, Rhina (2012). Transnacionalismo y modelos de codesarrollo: impacto en el desarrollo local de las comunidades de origen. Estudio de caso: El Salvador y Colombia. Tesis doctoral. Madrid: Universidad Complutense de Madrid.

Cortés, Almudena (2004). «La emergencia del codesarrollo: una emergencia transnacional». Actas del IV Congreso sobre la Inmigración en España: Ciudadanía y Participación (10-13 de noviembre).

Cortés, Almudena y Sanmartín, Anna (2010). «Las prácticas transnacionales de los/ as migrantes vinculadas al desarrollo. Un estudio a partir del contexto español». Revista del Ministerio de Trabajo e Inmigración, 80, 191-210.

Crespo, Rafael (2015). «Más de una década de codesarrollo, ¿qué hemos aprendido? La visión de un Tubab. Propuesta de análisis desde la perspectiva intercultural». En: García, F. Javier; Megías, Adelaida y Ortega, Jennifer (eds.). Actas del VIII 
Congreso sobre Migraciones Internacionales en España (Granada, 16-18 de septiembre de 2015). Granada: Instituto de Migraciones.

FAIST, Thomas (2010). «Transnationalization and Development: Toward and Alternative Agenda». En: Glick-Schiller, Nina y Faist, Thomas (eds.). Migration, Development and Transnationalization. EE. UU.: Berghahn Books.

Garreta, Jordi y Guillem, Xavier (2010). «Introducción. Migraciones y codesarrollo». En: Solé, Carlota (coord.). Migraciones y desarrollo. El codesarrollo: del discurso a la práctica. Barcelona: Anthropos.

Giménez, Carlos (2010). «Prólogo. A favor del codesarrollo. Una llamada al diálogo y la cooperación». En: Lacomba, Joan y Falomir, Fernando (eds.). De las migraciones como problema a las migraciones como oportunidad. Codesarrollo y movimientos migratorios. Madrid: La Catarata.

Giménez, Carlos; Martínez, Julio L.; Fernández, Mercedes y Cortés, Almudena (2006). El codesarrollo en España. Protagonistas, discursos y experiencias. Madrid: La Catarata.

Gómez, Carlos (2005). «Nuevas vías para el codesarrollo en la cooperación descentralizada». Cuadernos Bakeaz, 72, 1-16.

Gómez, Carlos y Unzueta, Amaia (2009). Manual para una mejor intervención en el codesarrollo. Bilbao: Bakeaz-SI.

GonZÁLEZ, Ángel (2015). «Migraciones, seguridad y cooperación internacional: la ayuda oficial al desarrollo como herramienta de control migratorio». En: GARcía, F. Javier; Megías, Adelaida y Ortega, Jennifer (eds.). Actas del VIII Congreso sobre Migraciones Internacionales en España (Granada, 16-18 de septiembre de 2015). Granada: Instituto de Migraciones.

GozÁlvez, Vicente (2012). «El proceso de inmigración extranjera en España, 19852010)». En: Argene, Marisa; Pace, Roberta y Girone, Stefania (eds.). II Mediterraneo: uno studio e una passione. Bari: Cacucci Editore.

Herrero de Egaña, Blanca (2012). "Suena bien eso del codesarrollo, pero... exactamente ¿qué es? Reflexiones sobre el codesarrollo desde experiencias prácticas». En: Aboussi, Mourad (coord.). El codesarrollo a debate. Granada: Editorial Comares.

LAсомва, Joan (2010). «El codesarrollo: debilidades y fortalezas de una idea y su práctica». En: Solé, Carlota (coord.). Migraciones y desarrollo. El codesarrollo: del discurso a la práctica. Barcelona: Anthropos.

- (2012). «El codesarrollo visto desde el Mediterráneo. Lecciones a partir del caso marroquí». En: Aвоussi, Mourad (coord.). El codesarrollo a debate. Granada: Editorial Comares.

Lacomba, Joan y Royo, Isabel (2020). «Los ODS y la sociedad civil migrante. El encaje de las asociaciones de inmigrantes en las políticas de cooperación al desarrollo en España». Iberoamerican Journal of Development Studies, 9 (1), 232-257. <https://doi.org/10.26754/ojs_ried/ijds.458>

Lacroix, Thomas (2009). Migrations, Développement, Codéveloppement: quels acteurs pour quels discours? París: HAL. Recuperado de <https://halshs.archives-ouvertes. $\mathrm{fr} /$ halshs-00820369>.

LeY 23/1998, de 7 de julio, de Cooperación Internacional para el Desarrollo. Boletín Oficial del Estado. Recuperado de <https://www.boe.es/buscar/doc.php?id=BOEA-1998-16303>.

López-SAla, Ana María (2007). «La política española de inmigración en las dos últimas décadas. Del asombro migratorio a la política en frontera y la integración». En: 
Arango Vila-Belda, Joaquín (ed.). Inmigración en Canarias: contexto, tendencias y retos. Madrid: Fundación Pedro García Cabrera.

Lubián, Carlos (2012). "Codesarrollo: ¿una herramienta de la cooperación?». En: Авоussi, Mourad (coord.). El codesarrollo a debate. Granada: Editorial Comares.

Malgesini, Gabriela (2001). "Reflexiones sobre migraciones, cooperación y codesarrollo». Arxius de Ciències Socials, 5, 123-146.

Marín, Isabel (2006). La cooperación española para el desarrollo como prevención de la emigración marroqui: percepciones, discursos y realidades entre dos orillas. Tesis doctoral. Granada: Universidad de Granada.

Ministerio de Asuntos Exteriores (2000). Plan Director de la Cooperación Española 2001-2004. Madrid: Ministerio de Asuntos Exteriores.

Ministerio de Asuntos Exteriores y Cooperación (2005). Plan Director de la Cooperación Española 2005-2008. Madrid: Ministerio de Asuntos Exteriores y Cooperación.

- (2008). Principales líneas de actuación en Migración y Desarrollo. Febrero 2008. Madrid: Ministerio de Asuntos Exteriores y Cooperación.

- (2009). Plan Director de la Cooperación Española 2009-2012. Madrid: Ministerio de Asuntos Exteriores y Cooperación.

- (2013). Plan Director de la Cooperación Española 2013-2016. Madrid: Ministerio de Asuntos Exteriores y Cooperación.

- (2018). V Plan Director de la Cooperación Española 2018-2021. Madrid: Ministerio de Asuntos Exteriores y Cooperación.

Ministerio del Interior (2001). Programa Global de Regulación y Coordinación de la Extranjería y la Inmigración. Madrid: Ministerio del Interior.

Monsutti, Alessandro (2008). "Migration et développement: une histoire de brouilles et de retrouvailles». Annuaire Suisse de Politique de Développement, 27 (2), 23-42. $<$ https://doi.org/10.4000/aspd.162>

NAÏr, Sami (1997). Informe de balance y orientación de la política de codesarrollo en relación con los flujos migratorios. Misión Interministerial sobre Migración y Codesarrollo. Ministerio de Asuntos Exteriores de Francia.

- (2003). «Flujos migratorios y codesarrollo: ¿Qué política para la Unión Europea?». En: Mariño, Fernando M. (dir.). Derecho de Extranjería, Asilo y Refugio. Madrid: Ministerio de Trabajo y Asuntos Sociales.

- (2008). «Codéveloppement et flux migratoires». Migrations Société, 3 (117-118), 71-76. <https://doi.org/10.3917/migra.117.0071>

PinYol, Gemma (2019). "En construcción": veinte años de política de inmigración y asilo de la UE». Agenda Pública. Recuperado de <https://agendapublica.es/en-construccion-veinte-anos-de-politica-de-inmigracion-y-asilo-de-la-ue/>.

Pinyol, Gemma y Royo, Enric (2010). «El concepto de codesarrollo en las políticas públicas: una historia inconclusa». En: Solé, Carlota (coord.). Migraciones y desarrollo. El codesarrollo: del discurso a la práctica. Barcelona: Anthropos.

SAID, Edward W. (1996). Cultura e imperialismo. Barcelona: Editorial Anagrama.

SANMARTín, Anna (2011). "Las asociaciones de migrantes en las actuaciones de codesarrollo. Un estudio de caso desde la ciudad de Madrid». Migraciones, 30, 71-99.

Shore, Cris (2010). "La Antropología y el estudio de la política pública: reflexiones sobe la "formulación" de las políticas". Antípoda, 10, 21-49. $<$ https://doi.org/10.7440/antipoda10.2010.03> 
Sotillo, José Ángel (2016). «La cooperación para el desarrollo y las relaciones internacionales». En: Echart, Enara; Cabezas, Rhina y Sotillo, José Ángel (coords.). Manual para la elaboración de investigaciones en cooperación para el desarrollo. Madrid: La Catarata.

Zapata-Barrero, Ricard; GonzÁlez, Elisabet y Sánchez, Elena (2008). El discurso político en tono a la inmigración en España y la Unión Europea. Madrid: Ministerio de Trabajo e Inmigración.

\section{Anexos}

Cuadro 3. Documentos analizados

\begin{tabular}{|c|c|c|c|}
\hline Año & Organismo & Título del documento & Denominación \\
\hline 1998 & $\begin{array}{l}\text { Gobierno de España, Boletín } \\
\text { Oficial del Estado }\end{array}$ & $\begin{array}{l}\text { Ley } 23 / 1998 \text {, de } 7 \text { de julio, de } \\
\text { Cooperación Internacional para } \\
\text { el Desarrollo }\end{array}$ & Ley $23 / 1998$ \\
\hline 2000 & Ministerio de Asuntos Exteriores & $\begin{array}{l}\text { Plan Director de la Cooperación } \\
\text { Española 2001-2004 }\end{array}$ & I PD (2001-2004) \\
\hline 2005 & $\begin{array}{l}\text { Ministerio de Asuntos Exteriores } \\
\text { y Cooperación }\end{array}$ & $\begin{array}{l}\text { Plan Director de la Cooperación } \\
\text { Española 2005-2008 }\end{array}$ & II PD (2005-2008) \\
\hline 2009 & $\begin{array}{l}\text { Ministerio de Asuntos Exteriores } \\
\text { y Cooperación }\end{array}$ & $\begin{array}{l}\text { Plan Director de la Cooperación } \\
\text { Española 2009-2012 }\end{array}$ & III PD (2009-2012) \\
\hline 2013 & $\begin{array}{l}\text { Ministerio de Asuntos Exteriores } \\
\text { y Cooperación }\end{array}$ & $\begin{array}{l}\text { Plan Director de la Cooperación } \\
\text { Española 2013-2016 }\end{array}$ & IV PD (2013-2016) \\
\hline 2018 & $\begin{array}{l}\text { Ministerio de Asuntos Exteriores } \\
\text { y Cooperación }\end{array}$ & $\begin{array}{l}\text { V Plan Director de la Cooperación } \\
\text { Española 2018-2021 }\end{array}$ & V PD (2018-2021) \\
\hline 2002 & $\begin{array}{l}\text { Ministerio de Asuntos Exteriores } \\
\text { y Cooperación }\end{array}$ & $\begin{array}{l}\text { Plan Anual de Cooperación } \\
\text { Internacional } 2002\end{array}$ & PACI (2002) \\
\hline 2003 & Ministerio de Asuntos Exteriores & $\begin{array}{l}\text { Plan Anual de Cooperación } \\
\text { Internacional } 2003\end{array}$ & PACI (2003) \\
\hline 2004 & Ministerio de Asuntos Exteriores & $\begin{array}{l}\text { Plan Anual de Cooperación } \\
\text { Internacional } 2004\end{array}$ & PACI (2004) \\
\hline 2005 & $\begin{array}{l}\text { Ministerio de Asuntos Exteriores } \\
\text { y Cooperación }\end{array}$ & $\begin{array}{l}\text { Plan Anual de la Cooperación } \\
\text { Internacional } 2005\end{array}$ & PACI (2005) \\
\hline 2006 & $\begin{array}{l}\text { Ministerio de Asuntos Exteriores } \\
\text { y Cooperación }\end{array}$ & $\begin{array}{l}\text { Plan Anual de Cooperación } \\
\text { Internacional } 2006\end{array}$ & PACI (2006) \\
\hline 2007 & $\begin{array}{l}\text { Ministerio de Asuntos Exteriores } \\
\text { y Cooperación }\end{array}$ & $\begin{array}{l}\text { Plan Anual de Cooperación } \\
\text { Internacional } 2007\end{array}$ & PACI (2007) \\
\hline 2008 & $\begin{array}{l}\text { Ministerio de Asuntos Exteriores } \\
\text { y Cooperación }\end{array}$ & $\begin{array}{l}\text { Plan Anual de Cooperación } \\
\text { Internacional } 2008\end{array}$ & PACl (2008) \\
\hline 2009 & $\begin{array}{l}\text { Ministerio de Asuntos Exteriores } \\
\text { y Cooperación }\end{array}$ & $\begin{array}{l}\text { Plan Anual de Cooperación } \\
\text { Internacional } 2009\end{array}$ & PACI (2009) \\
\hline 2010 & $\begin{array}{l}\text { Ministerio de Asuntos Exteriores } \\
\text { y Cooperación }\end{array}$ & $\begin{array}{l}\text { Plan Anual de Cooperación } \\
\text { Internacional } 2010\end{array}$ & PACI (2010) \\
\hline 2011 & $\begin{array}{l}\text { Ministerio de Asuntos Exteriores y } \\
\text { Cooperación }\end{array}$ & $\begin{array}{l}\text { Plan Anual de Cooperación } \\
\text { Internacional } 2011\end{array}$ & PACI (2011) \\
\hline
\end{tabular}


Cuadro 3. Documentos analizados (continuación)

\begin{tabular}{|c|c|c|c|}
\hline Año & Organismo & Título del documento & Denominación \\
\hline 2012 & $\begin{array}{l}\text { Ministerio de Asuntos Exteriores } \\
\text { y Cooperación }\end{array}$ & $\begin{array}{l}\text { Plan Anual de Cooperación } \\
\text { Internacional } 2012\end{array}$ & PACI (2012) \\
\hline 2013 & $\begin{array}{l}\text { Ministerio de Asuntos Exteriores } \\
\text { y Cooperación }\end{array}$ & $\begin{array}{l}\text { Plan Director de la Cooperación } \\
\text { Española 2013-2016. Comunica- } \\
\text { ción } 2013\left(2 .^{\circ} \text { semestre) }\right.\end{array}$ & $\begin{array}{l}\text { Comunicación } \\
2013\end{array}$ \\
\hline 2014 & $\begin{array}{l}\text { Ministerio de Asuntos Exteriores } \\
\text { y Cooperación }\end{array}$ & $\begin{array}{l}\text { Plan Director de la Cooperación } \\
\text { Española 2013-2016. Comunica- } \\
\text { ción } 2014 \text { al Parlamento y al } \\
\text { Consejo de Cooperación }\end{array}$ & $\begin{array}{l}\text { Comunicación } \\
2014\end{array}$ \\
\hline 2015 & $\begin{array}{l}\text { Ministerio de Asuntos Exteriores } \\
\text { y Cooperación }\end{array}$ & $\begin{array}{l}\text { Plan Director de la Cooperación } \\
\text { Española 2013-2016. Comunica- } \\
\text { ción } 2015 \text { al Parlamento y al } \\
\text { Consejo de Cooperación }\end{array}$ & $\begin{array}{l}\text { Comunicación } \\
2015\end{array}$ \\
\hline 2019 & $\begin{array}{l}\text { Ministerio de Asuntos Exteriores, } \\
\text { Unión Europea y Cooperación }\end{array}$ & $\begin{array}{l}\text { Comunicación 2019. Recuperar } \\
\text { la política de cooperación para } \\
\text { el desarrollo }\end{array}$ & $\begin{array}{l}\text { Comunicación } \\
2019\end{array}$ \\
\hline 2001 & Ministerio del Interior & $\begin{array}{l}\text { Programa Global de Regulación } \\
\text { y Coordinación de la Extranjería } \\
\text { y la Inmigración }\end{array}$ & Plan GRECO \\
\hline 2008 & $\begin{array}{l}\text { Ministerio de Asuntos Exteriores y } \\
\text { Cooperación }\end{array}$ & $\begin{array}{l}\text { Principales líneas de actuación } \\
\text { en migración y desarrollo. } \\
\text { Febrero } 2008\end{array}$ & Líneas M\&D \\
\hline 2007 & $\begin{array}{l}\text { Ministerio de Trabajo y Asuntos } \\
\text { Sociales }\end{array}$ & $\begin{array}{l}\text { Plan Estratégico de Ciudadanía } \\
\text { e Integración 2007-2010 }\end{array}$ & PECI 2007-2010 \\
\hline 2011 & $\begin{array}{l}\text { Ministerio de Trabajo y Asuntos } \\
\text { Sociales }\end{array}$ & $\begin{array}{l}\text { Plan Estratégico de Ciudadanía } \\
\text { e Integración 2011-2014 }\end{array}$ & PECI 2011-2014 \\
\hline
\end{tabular}

Fuente: elaboración propia. 
